\title{
Examination of the Relationship between Renewable Energy and Economic Performance
}

\author{
H. Boubou' ${ }^{1}$, J. T. KisS ${ }^{2}$ \\ 1University of Debrecen, Doctoral School of Károly Ihrig Doctoral School of Management and Business, \\ hayyan.boubou@gmail.com \\ ${ }^{2}$ University of Debrecen, Faculty of Engineering, Department of Engineering Management and Enterprise, \\ tkiss@eng.unideb.hu
}

\begin{abstract}
Many countries are making considerable efforts to achieve solutions to environmental problems that we face today and developing renewable energy resources is one of the potential long-term solutions that constitute an absolute priority from a sustainable development perspective. The usage of renewable energy is one of the critical future challenges to reduce greenhouse gas emission and decrease energy dependency at the same time. Thus, replacing traditional energy sources with renewable ones, like Hydropower and wind power to produce electricity instead of fossil fuel. The objective of this study is to find a relationship between renewable energy consumption, macroeconomic factors, and the environment. There is a reliable and significant (at 1\% significant level) association between REC with GHG and GDP and a relatively strong association with EC.
\end{abstract}

Keywords: European Union, greenhouse gas emission, gross domestic product, renewable energy consumption.

\section{Introduction}

Recently a significant concern has been raised upon the environmental problems that come along with energy production using fossil fuel, which mainly appears in the greenhouse gas emission along with ozone depletion, global warming, air pollution, and other environmental issues. The energy consumption's growth is the concern of many economists and policymakers as for its importance for societies sustainability and future, fossil-fuel-based energy has a lifespan that will perish and will do great harm to the environment before that as well. On the other hand, renewable energy sources can be considered as environmentally benign energy sources, with its facilities caring a minimal impact on their surroundings. However, it is essential not only combating climate change, reduce $\mathrm{CO} 2$ emission and protection the environment and biodiversity, but also crucial energy efficiency improvement, and reduce energy dependence in different countries.

According to the European Parliament resolution on the Energy roadmap 2050, a future with energy "stresses that basing the energy systems of EU Member States on their energy resources, and on their ability to access them, is an essential pillar of the EU's energy security; believes, therefore, that from this perspective it would be most rational for the Member States to develop those energy technologies for 
which they have potential and experience, and which guarantee them a continuous and stable supply of energy while maintaining environmental and climate standards" (European Parliament, 2016:62).

These serious environmental issues encouraged many countries including the European Union (EU) to act upon finding alternative energy sources to fit energy needs and almost harmless to the environment, while at the same time facing the rising energy demand, instable prices, and disruptions to supply.

In order to increase the share of renewable energy sources (RES) as a source of energy has a high priority in the energy strategies of many countries. EU has set itself clear targets for 2020, 2030, and 2050 to reach a reduction of greenhouse gas emission (GHG) by $80-95 \%$, for 2050 (at least 20\% and $40 \%$ cut in GHG for 2020 and 2030, respectively) (European Commission, 2019).

The research objectives are laying out a simple analysis to check if there a relationship between the renewable energy consumption (REC) and the macroeconomic variables, gross domestic product (GDP), energy consumption (EC) along with the environment effect represented by greenhouse gas emission (GHG).

\section{Brief Literature Review}

There are various reasons for increasing the production and consumption of renewable energy sources, such as the environmental problems, reduce the impact of energy supply on the environment (e.g. greenhouse gas emission, air pollution), and reduction the dependency on foreign energy sources, and replace them with domestic renewable energy sources. At the same time, there are concerns about the safety of nuclear power plants in some countries.

Fossil fuels, mainly crude oil, are confined to specific areas in the world, and the continuity of supply is controlled by political, economic and ecological factors (Frano - Ulgiati, 2008).

Moreover, due to its uneven natural distribution, reserves for fossil fuels are limited and extreme consumption of fossil fuels has a significant adverse effect on the environment and climate change; this excessive consumption also leads to amplified health risks (Farhard, et al., 2008).

Under the light of these facts, we can see that fossil fuels can be neither a permanent solution nor practical remedy for the world's current or future energy need. Hence, establishing any method which could reduce fossil fuels consumption is valuable (Farhard, et al., 2008).

\subsection{The Economic Effect of Renewable Energy}

Renewable energy jobs in Europe have increased in recent years, with the new developments in the industry, backed up with the support of the European Union's policies along with the increase in the overall awareness about the climate change.

Based on the International Renewable Energy Agency (IRENA, 2016) study (Renewable Energy Benefits), the accelerating the deployment of renewable energy will fuel economic growth, create new employment opportunities, enhance human welfare, and contribute to a safe climate future. The IRENA (2016) states that doubling the share of renewable energy in the global energy mix by 2030 would increase global GDP in 2030 between $0.6 \%$ and $1.1 \%$ compared to business as usual. 
These positive influences on GDP emerge from the increased investment in renewable energy deployment, which can cause ripple effects throughout the economy (IRENA, 2016). However, researchers and policymakers try to reveal not only the economic impacts of renewable energy but also a positive effect on welfare. Based on the Renewable Energy Benefits Report (IRENA, 2016), doubling the share of renewable energy by 2030 has a positive effect on global well-being, which increases by 2.7 $\%$. A combined indicator of prosperity considers several factors, including:

- Economic based impacts on consumption and investment;

- Social results based on expenditure on health and education; and

- Environmental impacts, measured as greenhouse gas emissions and materials consumption (IRENA, 2016).

According to the IRENA's examination for the relationship between renewable energy and job creation (2018), the number of jobs in the European Union reached 1.19 million, which is promising as if compared to the year 2015 as they were 1.16 million increasing by 30 thousand jobs a year (IRENA, 2018). The majority of the careers provided by Biomass and Wind Power, around 366 thousand jobs during the year 2016 alone, with a growing policy boost for the Biomass sector, however, this sector is concentrated only in a 6 European countries: Germany, France, Spain, Italy, Poland and Finland (IRENA, 2018). The wind industry remains one of the top remarks of the Renewable Energy sector in Europe, with many of its countries taking place at the top 10 countries in the world with the biggest installed Wind Turbines. IRENA (2018) estimated that in Germany alone in 2016, almost half of the renewable jobs are Wind Power related jobs, with a respected share of Wind jobs in other European Countries. The United Kingdom onshore wind market grew in 2016 almost three times as the previous year providing plenty of jobs.

European Biofuel sector according to IRENA (2018) provided jobs for around 170 thousand in 2015, on the other hand during that the Solar sector is continuing to decrease in terms of employment by almost 10 thousand jobs less in 2016 than what it was in 2015. In Poland, the decrease in this sector was severe as it went down by $50 \%$, on the other renewable energy sector the jobs were steadily increasing concerning their sector development (IRENA, 2018).

In more European specific analysis on the Renewable Energy effects on welfare, a recent study by Bachner (2019) examined the macroeconomic feedback effects of increasing the renewable energy share in electric generation in Europe based on the generation cost, intensity of generation technologies, and the results were of a positive impact in all the variety of the regions. However, when the integration cost is included, the effects were much lower with sometimes even turning into adverse effects in some cases. The writers explained these negative association due to the highest market cost for thermal power plants, and due to a high capital intensity in PV and wind. The result was a county-specific as in some countries in Western, Northern and Eastern Europe, the wind power has higher welfare than PV, on the other hand, the case was reversed in Southern, and Eastern Europe with a great deal of welfare is for PV (Bachner, 2019). 


\subsection{The Relationship between GDP, Energy and Renewable Energy Consumption}

Many studies have examined the relationship between energy, renewable energy consumption and economic growth both in developed and developing countries, focusing on multiple periods, different variables, and econometric methodologies, mainly regarding the gross domestic product (GDP), CO2 emissions, capital investments and other parameters (Fallahi, 2011; Guillet, 2010; Ohler - Fellers, 2014; Mohsen et al., 2015; Soytas et al., 2003, Payne, 2009a; 2010; 2011; Sari et al., 2008; Yuxue - Haitao, 2016; Wang et al., 2011; Wong et al., 2013). In the existing studies, a clear answer cannot be found a relationship between GDP and energy consumption.

Payne (2009a) reveals four hypotheses ('growth hypothesis', the 'conservation hypothesis', the 'feedback hypothesis,' and the 'neutrality hypotheses) which have emerged within the energy economics literature testing the relationship between energy consumption and economic growth. On the bases of the growth hypothesis, energy consumption may result in economic growth (Yang, 2000; Chen et al., 2007, Sari et al., 2008). Contrary to the growth hypothesis, the conservation hypothesis states that there is unidirectional causality from economic growth to energy consumption (Mallick, 2009; Soytas et al., 2003). However, according to the feedback hypothesis, there is a bidirectional relationship between energy consumption and economic growth (Apergis - Payne, 2009; Belloumi, 2009; Yuxue - Haitao, 2016), while the neutrality hypothesis states that there is no relationship between the two macroeconomic indicators (Ozturk - Acaravci, 2010).

The studies in this area can be classified into three groups based on the method used to analyse the relationship between renewable energy consumption and economic growth. The first class of studies is related to analyse the direction of the causal relationship between the variables, using several causality tests. For instance, Toda and Yamamoto causality test, ADRL bound testing approach, Engle-Granger causality, and Vector Error Correction causality tests, which all related to the empirical causality context (Payne, 2009b; Sadorsky, 2009). The second class of studies used cross-section panels, finding the causal relationship between energy consumption and economic growth over time for different countries not taking into consideration the country-specific economy, failing by that presenting a fair model (Chang et al., 2009; Apergis - Payne, 2010). The last class of studies is based on the SVAR model, which is not commonly used in energy economics studies, and there are just a few on this model (Silva, 2012).

\section{Data and Method}

The data used in this study are annual data for the European Union EU (28 countries), collected for a 17-year period, 2000-2016, all the data were taken from the European Commission Eurostat Database. The data collected for 28 countries and each country has its specification in terms of significant events that affect that country only. For this study, the data were taken for the EU as a whole.

Greenhouse gas emission (GHG) data were available on Eurostat only for the period between 2000 and 2016, so we could not analyse a more extensive set of data. 
The Renewable Energy Consumption (REC) is the supply, transformation and consumption of renewable energies - annual data (thousand tons of oil equivalent (TOE)). Renewable energies include Hydropower, Wind power, Solar thermal, and Solar Photovoltaic. GHG is the greenhouse emission (tones of $\mathrm{CO} 2$ equivalent per capita). The 'Kyoto basket' of greenhouse gases includes carbon dioxide (CO2), methane (CH4), nitrous oxide (N2O), and the so-called F-gases (hydrofluorocarbons, perfluorocarbons, nitrogen trifluoride (NF3) and Sulphur Hexafluoride (SF6). EC is the energy consumption in household per capita (kg of oil equivalent). The indicator measures how much electricity and heat every citizen consumes at home, excluding energy used for transportation (Eurostat, 2019). Since the indicator refers to final energy consumption, only energy used by end consumers is considered. The related consumption of the energy sector itself is excluded, GDP is the Gross Domestic Product per capita (measured in Euro).

\begin{tabular}{|c|c|c|c|}
\cline { 2 - 4 } \multicolumn{1}{c|}{} & $\begin{array}{c}\text { GDP } \\
\text { (Euro per } \\
\text { capita) }\end{array}$ & $\begin{array}{c}\text { GHG } \\
\text { (Tones of CO2 } \\
\text { equivalent per } \\
\text { capita) }\end{array}$ & $\begin{array}{c}\text { EC } \\
\text { (Kg of oil } \\
\text { equivalent) }\end{array}$ \\
\hline Average for countries above EU 28 & 42885.7 & 11 & 766.357 \\
\hline EU 28 & 27100 & 8.7 & 563 \\
\hline Average for countries below EU 28 & 15473.3 & 8.62 & 488 \\
\hline
\end{tabular}

Table 1: Average GDP, GHG, and EC for countries above and below EU28 average in 2016.

Source: Authors' calculation

Based on Table 1, we can see that the higher the GDP is the higher the possibility that the country has above average GHG and EC. The countries with a stronger economy or higher GDP are responsible for the higher share of GHG, with some countries that do not fit the above as well. In the case of Sweden, that has a high GDP than the average but less GHG, and the same for Estonia with a lower GDP than the average and way higher GHG.

The REC for the European Countries has increased during the examined period significantly. With 16 countries exceeding a 100\% increase in the REC and with the United Kingdom and Belgium exceeding five times increase in their consumption by 2016 than what it was in 2000 (Figure 1). That means that all the aspects of supply, transformation and use of renewable energies have increased including Hydropower, Wind power, Solar thermal, and Solar Photovoltaic. 


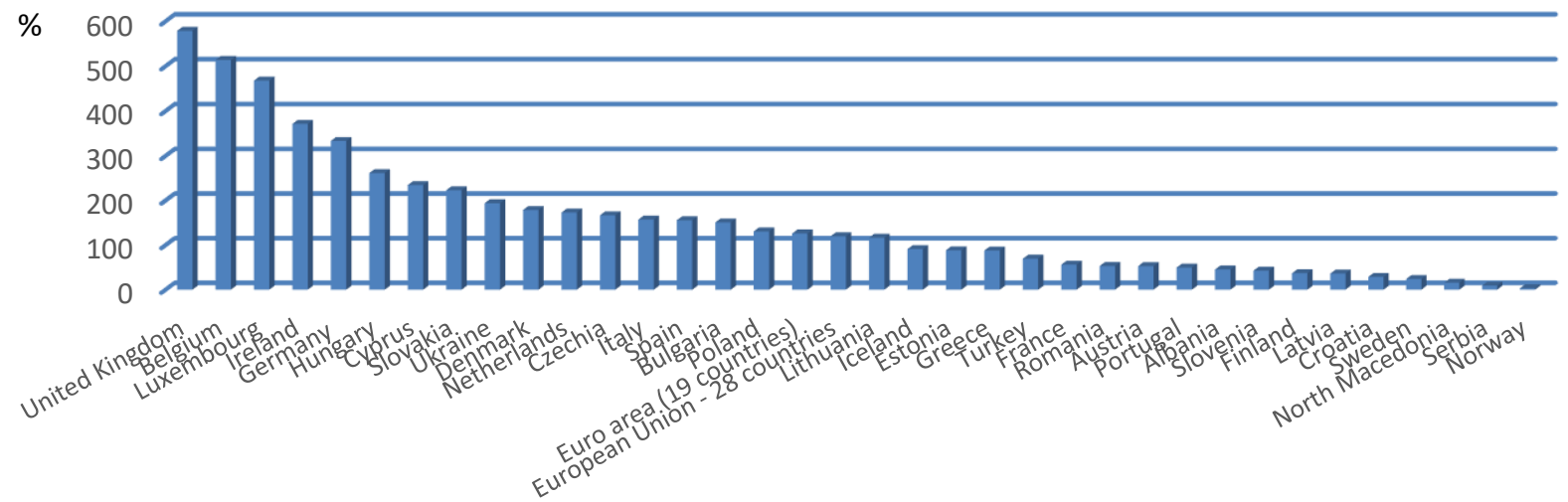

Figure 1. The percentage increase in REC between 2000 and 2016.

Source: Eurostat 2019

Most of the countries reduced their emission of GHG, with EU average of 19.5\% reduction (Figure 2), and we can see with some increase in GHG for some countries like Lithuania that increased by $28 \%$ even though REC has risen by $116.63 \%$.

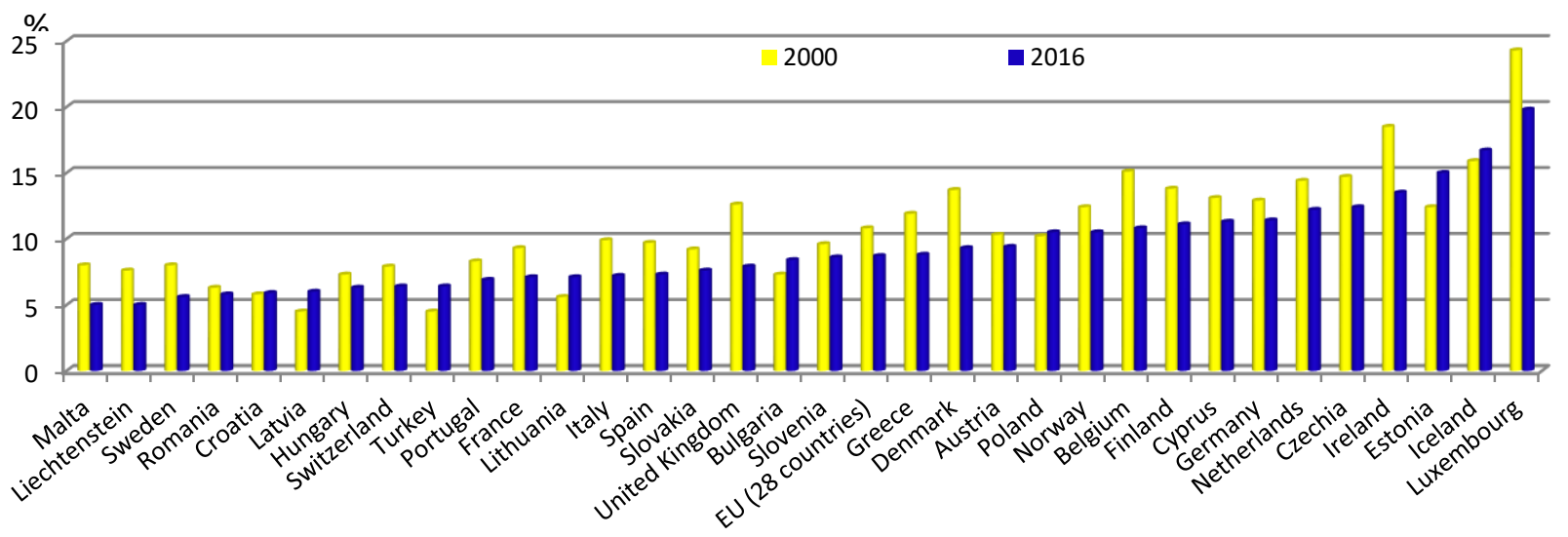

Figure 2: GHG emission in 2000 and 2016.

Source: Eurostat, 2019.

Taking a closer look to the first eight countries specifically with the highest increase (over 200\%) in the renewable energy consumption, we can see that the highest decrease in GHG occurred in the United Kingdom alone, it dropped 37\%, from what it was in 2000, exceeding the EU-28 which is $19.44 \%$ (Table 2). 


\begin{tabular}{|c|c|c|c|c|}
\hline \multicolumn{1}{|c|}{} & $\begin{array}{c}\mathbf{R E C} \\
\mathbf{( \% )}\end{array}$ & $\begin{array}{c}\text { GHG** } \\
\mathbf{( \% )}\end{array}$ & $\begin{array}{c}\text { EC } \\
\mathbf{( \% )}\end{array}$ & $\begin{array}{c}\text { GDP } \\
\mathbf{( \% )}\end{array}$ \\
\hline United Kingdom & 578.60 & 37.30 & $-19.81^{*}$ & 18.66 \\
\hline Belgium & 513.78 & 28.48 & -20.95 & 13.86 \\
\hline Luxembourg & 467.87 & 18.52 & -15.49 & 14.75 \\
\hline Ireland & 371.32 & 27.03 & -15.05 & 59.46 \\
\hline Germany & 333.20 & 11.63 & -14.34 & 20.34 \\
\hline Hungary & 261.37 & 13.70 & 14.21 & 43.04 \\
\hline Cyprus & 234.57 & 13.74 & 51.38 & 8.91 \\
\hline Slovakia & 223.05 & 17.39 & -22.08 & 87.18 \\
\hline EU 28 & 119.85 & 19.44 & -5.70 & 18.34 \\
\hline
\end{tabular}

Table 2: The variables percentage increase/decrease 2000-2016 for the top 8 countries, * The minus sign indicates a decrease in the EC. ** The indicator shows the decrease in GHG.

\section{Source: Authors' calculation}

The EC decreased through the period except for Hungary and Cyprus, as the EC increased even by over a half in case of Cyprus, this could be related to other factors that might affect the EC for these countries. However, the GDP for the above countries has increased significantly as well, and we can see in EU 28 the REC has doubled, with less EC, and more GDP, and deduction in GHG (Table 2.).

\section{Results}

Calculation of the Pearson correlation coefficient provides an idea about the nature and degree of the relationship between the variables separately.

\begin{tabular}{|c|c|c|c|c|}
\hline & REC & GHG & EC & GDP \\
\hline $\begin{array}{c}\text { REC } \\
\text { (Thousand tons of oil } \\
\text { equivalent) }\end{array}$ & 1 & 1 & & \\
\hline $\begin{array}{c}\text { GHG } \\
\text { (Tones of Co2 } \\
\text { equivalent per capita) }\end{array}$ &,$- 973^{* *}$ &, $735^{* *}$ & 1 & 1 \\
\hline $\begin{array}{c}\text { EC } \\
\text { (Kg of oil equivalent) }\end{array}$ &,$- 675^{* *}$ &,$- 735^{* *}$ &,$- 596^{*}$ & 1 \\
\hline $\begin{array}{c}\text { GDP } \\
\text { (Euro per capita) }\end{array}$ &, $846^{* *}$ & \multirow{2}{*}{$*$. Correlation is significant at the 0.01 level } \\
\hline & & & & \\
\hline
\end{tabular}

Table 3: The Pearson Correlation coefficients of the variables

Source: Authors' calculation 
If we can look first at REC, we can see that there is a reliable and significant (at $1 \%$ significant level) association between REC with GHG and GDP and a relatively strong association with EC. The correlation coefficient is positive for REC against GDP and negative against GHG, and EC (Table 3). That refers respectively to a positive and a negative correlation between them. However, there is no information on the causation. Therefore, the change in on REC can cause the difference in the rest of the variables, or vice versa. Based on the correlation coefficients, we can assume that the countries with higher GDP have a greater possibility to invest and apply renewable energy resources. However, as we mentioned the direction of the causality is not known, the similar way the renewable energy production and consumption can have a positive effect on the level of the GDP. As we expected, there is a strong and negative relationship between the GHG and renewable energy consumption (at $1 \%$ significant level), that refer to the substitution of fossil with renewable energy has a positive effect on the level of GHG emission (Table 3).

\section{Conclusions}

The result of this study found a strong correlation between the defined variables and that there is a link between the noticeable increase in the usage of renewable energy sources. Thus, there is a decrease in the greenhouse gas emission along with what it appears as a positive relation between renewable energy usage and gross domestic product and energy consumption.

The result of the analysis shows a great deal of relationship between the variables. However, the study does not show any causality for the relationship between the variables. However, on the other hand, it clearly shows that by using a simple data analysis method, a correlation can be identified between the variables. In conclusion, it might present evidence empowering the current efforts toward renewable energy sources used as a substitute of non-renewable energy sources (usually represented as fossil fuel sources), and support this transformation as a severe step for a better environment and a better economy.

\section{References}

[1] Apergis, N. - Payne, J. E. (2009). Energy consumption and economic growth: evidence from the Commonwealth of Independent States, Energy Economics. 31, 5. 641-647.

[2] Apergis, N. - J. E. Payne. "Energy consumption and growth in South America: Evidence from a panel error correction model." Energy Economics 32.6 (2010): 1421-1426.

[3] G. Bachner, K. W. Steininger, K. Williges, A. Tuerk. The economy-wide effects of large-scale renewable electricity expansion in Europe: The role of integration costs. Renewable Energy 134 (2019): 1369-1380. 
[4] Belloumi, M. (2009). Energy consumption and GDP in Tunisia: cointegration and causality analysis. Energy Policy, 37, 2745-2753.

[5] Chang, Ting-Huan, Chien-Ming Huang, and Ming-Chih Lee. "Threshold effect of the economic growth rate on the renewable energy development from a change in energy price: Evidence from OECD countries." Energy Policy 37.12 (2009): 5796-5802.

[6] Chen, S. T., Kuo, H. I., \& Chen, C. (2007). The relationship between GDP and electricity consumption in 10 Asian countries. Energy Policy, 35, 2611-2621

[7] European Commission, EU Climate Action, https://ec.europa.eu/clima/citizens/eu_en, Download time: 17.08.2019. 16:06.

[8] European Parliament, European Parliament resolution of 14 March 2013 on the Energy roadmap 2050, a future with energy, Official Journal of the European Union C 36, Volume 5929 January 2016, pp. 62. https://eur-lex.europa.eu/legalcontent/EN/TXT/PDF/?uri=0J:C:2016:036:FULL\&from=HU. Download time: 17.08.2019. $15: 41$.

[9] Eurostat (2019): Products datasets, Final energy consumption in households per capita, https://ec.europa.eu/eurostat/web/products-datasets/product?code=sdg_07_20.

Download time: 19.08.2019. 15:49

[10] F. Fallahi, "Causal relationship between energy consumption (EC) and GDP: A Markov switching (MS) causality", Energy, 36, 2011, pp. 4165-4170.

[11] S. Farhad, M. Saffar-Avval, and M. Younessi-Sinaki. "Efficient design of feedwater heaters network in steam power plants using pinch technology and energy analysis." International journal of energy research 32.1 (2008): 1-11.

[12] B. Frano, S. Ulgiati, eds., Sustainable energy production and consumption: benefits, strategies and environmental costing, pp. ix. Springer Science \& Business Media, 2008.

[13] R. Guillet, "Energy and economical growth: overview and global challenges", Environmental Engineering and Management Journal, 9, 2010, pp. 1357-1362.

[14] International Renewable Energy Agency (IRENA), Jobs. Renewable Energy and Job, Annual Review 2018." (2018).

[15] International Renewable Energy Agency (IRENA), Renewable energy benefits: measuring the Economics. https://www.irena.org/documentdownloads/publications/irena_measuringthe-economics_2016.pdf. Download time: 18.08.2019. 15:59.

[16] Mallick, H., Examining the linkage between energy consumption and economic growth in India. The Journal of Developing Areas, 2009. 43. pp. 249-280.

[17] M. Mohsen, R. Sadeq, D. H. Razi, Determinants of renewable energy consumption among ECO countries; Based on Bayesian model averaging and weighted-average least square, International Letters of Social and Humanistic Sciences, Vol. 54, 2015, pp. 96-109. 
[18] A. Ohler, I. Fetters, "The causal relationship between renewable electricity generation and GDP growth: A study of energy sources", Energy Economics, 43, 2014, pp. 125-139.

[19] Ozturk, I., \& Acaravci, A. (2010). Energy consumption and CO2 emissions economic growth in Turkey. Renewable and Sustainable Energy Reviews, 14(9), 3220-3225.

[20] J. E. Payne. "On the dynamics of energy consumption and employment in Illinois." Journal of Regional Analysis and Policy 39.1100-2016-89639 (2009a).

[21] J. E. Payne. "On the dynamics of energy consumption and output in the US." Applied energy 86.4 (2009b): 575-577

[22] J. E. Payne, "Survey of the international evidence on the casual relationship between energy consumption and growth", Journal of Economic Studies, 37, 2010, pp.53-95.

[23] J. E. Payne, “On Biomass Energy Consumption and Real Output in the US, Energy Sources”, Part B: Economics, Planning, and Policy, 6, 2011, pp. 47-52.

[24] Sadorsky, Perry. "Renewable energy consumption, CO2 emissions and oil prices in the G7 countries." Energy Economics 31.3 (2009): 456-462.

[25] Sari, R., Ewing, B. T., Soytas, U. (2008). The relationship between disaggregate energy consumption and industrial production in the United States: An ARDL approach. Energy Economics 30, 2302-2313.

[26] Silva, Susana, Isabel Soares, and Carlos Pinho. "The impact of renewable energy sources on economic growth and CO2 emissions-a SVAR approach." European Research Studies 15 (2012): 133.

[27] U. Soytas, R. Sari, Ozdemir, O "Energy consumption and GDP: causality relationship in G-7 countries and emerging markets", Energy Economics, 25, 2003, pp. 33-37.

[28] Y. Wang, Y. Wang, J. Zhou, X. Zhu, G. Lu, “Energy consumption and economic growth in China: A multivariate causality test”, Energy Policy, 39, 2011, pp. 4399-4406.

[29] S. L. Wong, Y. Chang, W. M. Chia, "Energy consumption, energy R\&D and real GDP in OECD countries with and without oil reserves", Energy Economics, 40, 2013, pp. 51-61.

[30] Yang, H. Y. (2000). A note on the causal relationship between energy and GDP in Taiwan. Energy economics, 22(3), 309-317.

[31] Yuxue, P. - Haitao, L. (2016). Electricity consumption and economic growth in the BeijingTianjin-Hebei agglomeration in China. Journal of Resources and Ecology, 7, 5. 360-371. 